\title{
Ranking Coal Ash Materials for Their Potential to Leach Arsenic and Selenium: Relative Importance of Ash Chemistry and Site Biogeochemistry
}

\author{
Grace E. Schwartz, ${ }^{1, *,+, *}$ James C. Hower, Allison L. Phillips, Nelson Rivera, \\ Avner Vengosh, and Heileen Hsu-Kim ${ }^{1, *, *}$ \\ ${ }^{1}$ Department of Civil and Environmental Engineering, Duke University, Durham, North Carolina. \\ ${ }^{2}$ Center for Applied Energy Research, University of Kentucky, Lexington, Kentucky. \\ ${ }^{3}$ Levine Science Research Center, Nicholas School of the Environment, Duke University, Durham, North Carolina. \\ ${ }^{4}$ Division of Earth and Ocean Sciences, Nicholas School of the Environment, Duke University, Durham, North Carolina.
}

Received: September 1, $2017 \quad$ Accepted in revised form: December 15, 2017

\begin{abstract}
The chemical composition of coal ash is highly heterogeneous and dependent on the origin of the source coal, combustion parameters, and type and configuration of air pollution control devices. This heterogeneity results in uncertainty in the evaluation of leaching potential of contaminants from coal ash. The goal of this work was to identify whether a single leaching protocol could roughly group high-leaching potential coal ash from lowleaching potential coal ash, with respect to arsenic (As) and selenium (Se). We used four different leaching tests, including the Toxicity Characteristic Leaching Protocol (TCLP), natural pH, aerobic sediment microcosms, and anaerobic sediment microcosms on 10 different coal ash materials, including fly ash, lime-treated ash, and flue gas desulfurization materials. Leaching tests showed promise in categorizing high and lowleaching potential ash materials, indicating that a single point test could act as a first screening measure to identify high-risk ash materials. However, the amount of contaminant leached varied widely across tests, reflecting the importance of ambient conditions ( $\mathrm{pH}$, redox state) on leaching. These results demonstrate that on-site geochemical conditions play a critical role in As and Se mobilization from coal ash, underscoring the need to develop a situation-based risk assessment framework for contamination by coal ash pollutants.
\end{abstract}

Keywords: arsenic; biogeochemistry; coal ash; disposal; leaching potential; selenium

\section{Introduction}

$\mathbf{C}$ OAL ASH IS composed primarily of three major solid waste streams: bottom ash, fly ash, and flue gas desulfurization (FGD) solids, and consists of a heterogeneous mixture of poorly to highly crystalline oxide phases of silicon, aluminum, calcium, and iron (Vejahati et al., 2010). Both the major and minor elemental composition of coal ash

*Corresponding authors: Grace E. Schwartz, Oak Ridge National Laboratory, PO Box 2008 MS6036, Oak Ridge, TN 37831-6036. Phone: (865) 241-2678; Fax: (865) 576-8646; E-mail: schwartzge@ ornl.gov or Heileen Hsu-Kim, Department of Civil and Environmental Engineering, Duke University, 121 Hudson Hall, Durham, NC 27708. Phone: (919) 660-5109; Fax: (919) 660-5219; E-mail: hsukim@duke.edu

${ }^{\dagger}$ Current affiliation: Oak Ridge National Laboratory, Environmental Sciences Division, Oak Ridge, Tennessee.

"Member of AEESP.

(C) Grace E. Schwartz et al. 2018; Published by Mary Ann Liebert, Inc. This Open Access article is distributed under the terms of the Creative Commons Attribution Noncommercial License (http:// creativecommons.org/licenses/by-nc/4.0/) which permits any noncommercial use, distribution, and reproduction in any medium, provided the original author(s) and the source are cited. are fundamentally determined by coal type and source, but combustion parameters and the configuration of air pollution control devices also influence how trace elements partition onto ash particles during combustion and particle capture processes (Vejahati et al., 2010). Trace elements may either coprecipitate with the crystalline oxide matrices of the ash or condense from the flue gas onto the ash particles (Meij, 1994; Vejahati et al., 2010).

The ability of fly ash particles to capture trace elements varies with particle surface area and flue gas temperature, with lower flue gas temperatures and high particle surface areas tending to increase trace element sorption or deposition on fly ash (Meij, 1994; Hower et al., 1999). Trace element concentrations in the ash materials vary according to the point of collection in the combustion process. Volatile trace elements, such as cadmium, chromium, lead, nickel, zinc, copper, vanadium, mercury, arsenic, and selenium are one to two orders of magnitude more concentrated in fly ash relative to bottom ash (Meij, 1994). FGD processes also efficiently capture watersoluble species, and the waste slurry from FGD is enriched in the most volatile elements, which include boron, carbon, sulfur, chlorine, bromine, nitrogen, mercury, and selenium (Meij, 1994; Vejahati et al., 2010; Córdoba et al., 2012). 
The trace element content in coal ash is most fundamentally linked to the source, type, and chemistry of the feed coal. Coal chemistry varies by coal basin and also within coal basins and formations. In the United States, western coals, such as those from the Powder River Basin, are known for their low sulfate $(<1 \%$ total sulfur) and low trace element content, whereas eastern coals tend to have higher sulfur content (Chou, 2012). Many trace elements in coal, such as arsenic (As), selenium (Se), antimony (Sb), mercury $(\mathrm{Hg})$, and lead $(\mathrm{Pb})$, are associated with sulfide minerals, particularly with pyrite (Finkelman, 1995; Kolker, 2012). Therefore, coals with high sulfur content also tend to have higher trace element content. Environmental damages have been reported for many trace element contaminants in coal ash due to improper disposal or ash spills (United States Environmental Protection Agency [US EPA], 2007). However, As and Se are of particular concern because of their propensity to leach during typical disposal scenarios and their potential for biomagnification in the food web of receiving water bodies (Luoma and Presser, 2009; Sharma and Sohn, 2009).

Previous studies show that the leachability of As and Se varies with the heterogeneity of ash material composition (Wang et al., 2009; Hutchinson et al., 2012; Izquierdo and Querol, 2012), and many leaching tests have been developed for coal ash in an attempt to account for diversity in leaching behavior for various contaminants. State and federal regulations guiding coal ash disposal have relied heavily on single point leaching tests, such as the EPA's Toxicity Characteristic Leaching Protocol (TCLP) (US EPA, 1992). With TCLP, the solid waste sample is leached overnight in an acidic solution ( $\mathrm{pH}=2.9$ or 5.0 ), and then the supernatant is analyzed for target contaminants of concern. While this test might be appropriate for many cationic metals and for landfill waste disposal, due to its single point acidic assessment, it can greatly underestimate the leaching potential of oxyanion contaminants such as arsenate $[\mathrm{As}(\mathrm{V})]$ and selenite [Se(IV)] (Thorneloe et al., 2010).

The Leaching Environmental Assessment Framework (LEAF) has been proposed as an alternative to TCLP, to better capture the $\mathrm{pH}$-dependent leaching of oxyanion contaminants. The LEAF considers a range of $\mathrm{pH}$ values (2-13), liquid-to-solid ratios, and mass transfer rates of contaminants over compacted media (US EPA, 2012a, 2012b, 2013a, $2013 b)$. Several leaching studies have also been conducted at the natural $\mathrm{pH}$ of ash materials in an attempt to better mimic the conditions found in coal ash impoundments (Catalano et al., 2012; Izquierdo and Querol, 2012; Liu et al., 2013). In sum, these leaching tests provide valuable information about the leaching behavior of contaminants under very specific conditions, but their applicability to field management scenarios is limited. The limitations of leaching tests are openly acknowledged by the EPA, which calls for the use of leaching tests in conjunction with field monitoring and geochemical modeling in formulating disposal plans (Kosson et al., 2009, 2014). Nevertheless, regulations guiding disposal continue to heavily rely on leaching tests for solid waste classification.

With this research, we sought to determine whether coal ash materials could be grouped into high- and low-leaching potential categories based on ash material chemistry. We subjected 10 different coal ash materials to four different leaching tests: in deionized (DI) water at the natural $\mathrm{pH}$ of the coal ash, the TCLP, and aerobic and anaerobic sediment slurry microcosm tests. The natural $\mathrm{pH}$ and TCLP tests were chosen to represent established protocols for determining leaching potential, while the anaerobic and aerobic microcosm tests were chosen, based on previous work (Schwartz et al., 2016a, 2016b), to be a closer representation of complex environmental conditions relevant for Se and As mobilization. The goal of this study was to determine whether these four leaching tests, which entailed a variety of leaching conditions and time points for assessment, could agree on the same high- and low-leaching potential rankings of the ash materials. The materials tested included seven fly ashes, one lime-treated fly ash sample, and two FGD samples. The leaching potential of the ash materials was then ranked for each test based on the amount of contaminant leached in $24 \mathrm{~h}$ per $g$ of coal ash test.

\section{Materials and Methods}

\section{Coal ash samples}

Ash materials (summarized in Table 1) were collected from various power plants across the United States between 2012 and 2013. The samples were selected to represent a range of coal sources and chemical characteristics, including $\mathrm{CaO}, \mathrm{SO}_{3}, \mathrm{Fe}_{2} \mathrm{O}_{3}$, and trace element content. The samples represented the three major coal basins in the United States ( 70-80\% of annual coal production) (United States Energy Information Administration [US EIA], 2014) and a variety of common air pollution control devices and ash collection methods (US EPA, 2013c). The major mineral oxide content in the ash was characterized via X-ray fluorescence following the ASTM standard method for ash analysis (Table 1). Trace element content was determined via heated nitric acid digestion followed by inductively coupled plasma-mass spectrometry (ICP-MS) (Agilent 7700). Details on the sample preparation method can be found in the Supplemental Data section.

\section{Natural $\mathrm{pH}$ leaching}

Natural $\mathrm{pH}$ leaching procedure was adapted from LEAF Protocol Method 1316 (United States Environmental Protection Agency, 2012b). Each coal ash material was mixed with Milli-Q water ( $2 \mathrm{~g}$ dry ash to $30 \mathrm{~mL}$ Milli-Q water) and tumbled end over end at $28 \mathrm{RPM}$ for $24 \mathrm{~h}$. The samples were then centrifuged at 4,000 RPM for $10 \mathrm{~min}$ and the supernatant was decanted and a portion was measured for $\mathrm{pH}$. The remaining supernatant was filtered through a $0.45-\mu \mathrm{m}$ nylon syringe filter (VWR) and diluted and acidified for ICP-MS analysis with $1-2 \%$ nitric acid to ensure that $\mathrm{pH}<2$. The ash materials were extracted in triplicate.

\section{TCLP procedures}

The TCLP testing procedure was adapted from EPA Method 1311 (US EPA, 1992). To determine which TCLP extraction fluid to use, $5 \mathrm{~g}$ of ash material was vigorously stirred in $96.5 \mathrm{~mL}$ of DI water for $5 \mathrm{~min}$. The $\mathrm{pH}$ was measured and recorded and $3.5 \mathrm{~mL}$ of $1 \mathrm{M} \mathrm{HCl}$ (Trace metal grade; Fisher) was added to the mixture. The solution was stirred briefly, heated to $50^{\circ} \mathrm{C}$, and held at $50^{\circ} \mathrm{C}$ for $10 \mathrm{~min}$. The solution was allowed to cool to room temperature and the $\mathrm{pH}$ was measured. For $\mathrm{pH}<5$, TCLP extraction fluid \#1 was selected. For $\mathrm{pH}>5$, TCLP extraction fluid \#2 was selected. Supplementary Table S1 lists the TCLP extraction fluid used for each ash sample. 


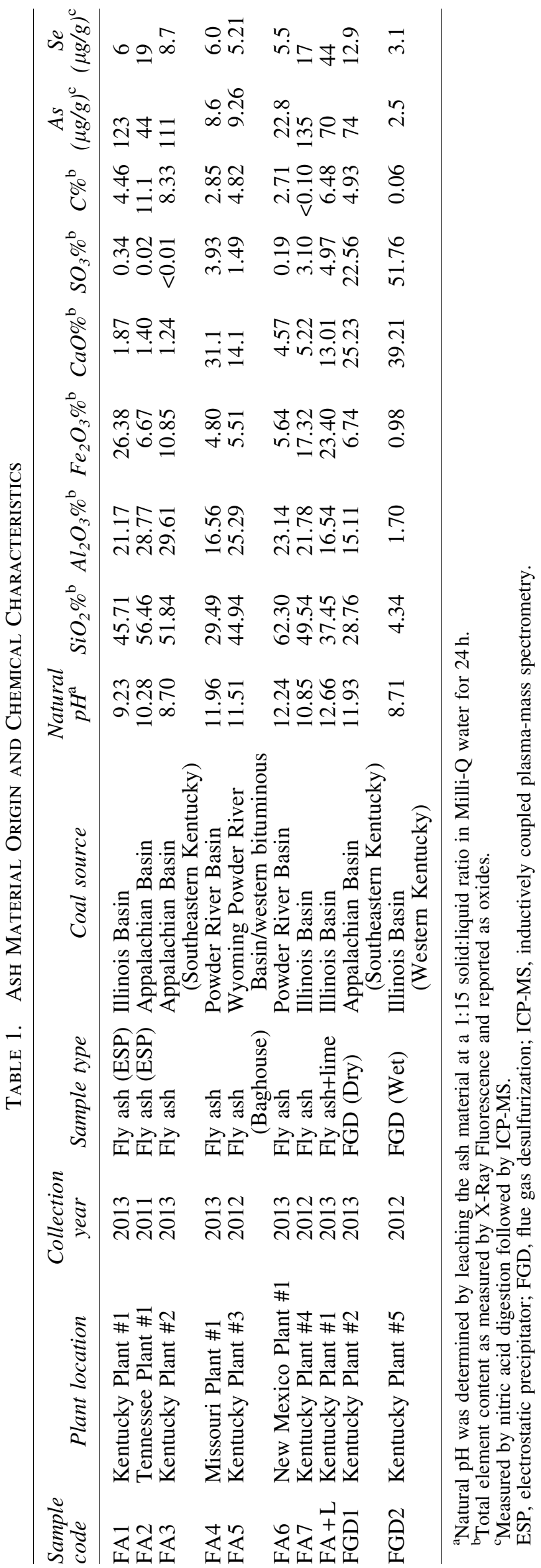

TCLP extraction fluid \#1 (pH 4.93 \pm 0.05$)$ was prepared with $5.7-\mathrm{mL}$ glacial acetic acid (Fisher) and $64.3 \mathrm{~mL}$ of $1-\mathrm{M}$ $\mathrm{NaOH}$ added to 1-L Milli-Q water. TCLP extraction fluid \#2 ( $\mathrm{pH} 2.88 \pm 0.05$ ) was comprised of 5.7-mL glacial acetic acid in 1-L of Milli-Q water. Each coal ash sample was leached at $2 \mathrm{~g}$ of dry fly ash to $40-\mathrm{mL}$ extraction fluid. The mixtures were tumbled end over end at $30 \pm 2 \mathrm{RPM}$ for $18 \mathrm{~h}$. The samples were then centrifuged at 4,000 RPM for $10 \mathrm{~min}$. The supernatant was filtered through a $0.45-\mu \mathrm{m}$ nylon syringe filter. The $\mathrm{pH}$ of the filtrate was measured, and the filtrate was parsed and preserved for ICP-MS analysis. The ash materials were extracted in triplicate.

\section{Sediment/ash slurry microcosms}

Microcosm experiment overview. The experiment entailed two sets of sediment incubation experiments: first under anaerobic conditions and next under aerobic conditions. The incubations ran 2 weeks with samples collected at $24 \mathrm{~h}$ and 14 days incubation time points. For both aerobic and anaerobic experiments, a sediment-water microcosm was prepared for each type of coal ash, which was added to a concentration of $25 \%(\mathrm{w} / \mathrm{w})$ relative to sediment (dry weight basis). This concentration of coal ash was chosen to represent a realistic sediment-ash mixture from an ash spill scenario (Deonarine et al., 2013). For each coal ash type, single slurries were prepared for anaerobic and aerobic experiments. Triplicate microcosms were prepared for the no-ash controls (sediment and water only) and for fly ash from Kentucky Plant \#2 (FA3). The FA3 sample was chosen for the triplicate preparation due to the abundance of our supply.

Sediment and water for microcosms. Surface water and bulk sediment were collected for microcosm construction from Jordan Lake near Pittsboro, NC (35.705004 $\left.{ }^{\circ},-79.047544^{\circ}\right)$ in October 2014. This sediment was selected because Jordan Lake was used as a reference lake in our previous field study on the impact of coal ash pond effluents in North Carolina lakes and rivers (Ruhl et al., 2012).

Surface water was collected from the top $0.15 \mathrm{~m}$ and was stored in acid-clean plastic jugs. Bulk sediment was collected by hand from the top layer of sediment (approximately top $15 \mathrm{~cm}$ ) and placed in a soap-cleaned (Micro-90) plastic bucket with screw top. The sediment and water were transported immediately to Duke University $(<45 \mathrm{~min})$ and stored at $4^{\circ} \mathrm{C}$ in the laboratory. The sediment and water were used to construct microcosms within 1 week of sampling. Major and trace elements in the sediments and water were quantified by nitric acid digestion followed by ICP-MS. The sediment As concentration was $3.58 \mu \mathrm{g} / \mathrm{g}$ and the Se concentration was $0.31 \mu \mathrm{g} / \mathrm{g}$. Further sediment chemistry is shown in Supplementary Table S2.

Microcosm preparation. Sediment was thoroughly homogenized by stirring before microcosm construction. The surface water was amended with a carbon source $(0.5-\mathrm{mM}$ pyruvate and 0.5-mM acetate; Sigma-Aldrich), which was used to maintain microbial activity. For both the aerobic and anaerobic experiments, an extra sediment-only microcosm was prepared and amended with 6-mg/L resazurin (SigmaAldrich) to serve as an indicator of redox conditions for all of the microcosms in the respective experiments. 
Anaerobic microcosms were constructed in $250-\mathrm{mL}$ acidwashed and autoclaved glass jars with air-tight screw top lids. These microcosms were prepared by combining $68 \mathrm{~g}$ of wet sediment and $170 \mathrm{~mL}$ of $\mathrm{N}_{2}$-purged surface water in an anaerobic chamber (Coy Labs) containing an ambient atmosphere of $90 \% \mathrm{~N}_{2(\mathrm{~g})}, 5 \% \mathrm{CO}_{2(\mathrm{~g})}$, and $5 \% \mathrm{H}_{2(\mathrm{~g})}$. The microcosms were then sealed in the anaerobic chamber but were stored outside the chamber at room temperature $\left(\sim 22^{\circ} \mathrm{C}\right)$ and were exposed to ambient laboratory light throughout the experiment. Anaerobic conditions $\left(\mathrm{E}_{\mathrm{H}}<-50 \mathrm{mV}\right)$ were achieved $\sim 7$ days after microcosm construction, as indicated by the resazurin indicator turning from pink to a clear color (Tratnyek et al., 2001). At this time, $11 \mathrm{~g}$ of coal ash sample was added to a designated microcosm, and the 2-week incubation with the ash was initiated. The microcosms were mixed end-over-end once every 1-2 days and before each sampling time point.

Aerobic microcosms contained the same amount of sediment and water as the anaerobic experiments, but were continuously purged with hydrated air inserted into the slurries through Teflon tubing. After 7 days of preincubation, coal ash was added to the aerobic microcosms. The microcosms were gently swirled to mix every $1-2$ days.

Microcosm sampling after ash addition. Overlying water was collected from the microcosms at time points before $(-1 \mathrm{~h})$ and after the ash material addition ( $24 \mathrm{~h}, 14$ days). For aerobic microcosms, the air bubblers were turned off during sampling, and the supernatant samples were immediately centrifuged at 3,000 RPM for $5 \mathrm{~min}$ and then filtered through a $0.2-\mu \mathrm{m}$ nylon syringe filter (VWR). For anaerobic microcosms, the supernatant was sampled in an anaerobic glove box and directly filtered (no centrifugation).

The sample filtrate was split and preserved for analysis of major and trace elements via ICP-MS, major anions via Ion Chromatography (Dionex), Dissolved Organic Carbon (Shimadzu TOC-L), and $\mathrm{pH}$. Whole slurry samples $(4 \mathrm{~mL})$ were taken at the 14-day time point for analysis of acid volatile sulfide. These aliquots were frozen at $-20^{\circ} \mathrm{C}$ immediately after sampling. Further details on sample preservation and analysis can be found in the Supplementary Data section.

\section{Statistical analyses}

Linear correlation analyses were performed using the statistical software package $R$ (GNU General Public License). For the microcosm linear correlations, the data sets (dissolved element concentrations and ash material total element concentrations) were assessed for normality using the Shapiro-Wilks test (significance cut off of $p=0.05$ ) and $\log _{10}$ transformed as necessary. Linear correlations between microcosm data sets (Supplementary Table S1) were deemed significant if the model obtained a $p$-value of 0.05 or less.

\section{Results and Discussion}

\section{Natural $\mathrm{pH}$ leaching}

Natural pH (ash material leached with DI water) of the ash materials ranged between 8.7 and 12.7 (Table 1). Dissolved As and Se concentrations varied widely between the ash samples and were observed to range from less than the method detection limit $(0.008 \mu \mathrm{g} / \mathrm{L}$ for As and $0.016 \mu \mathrm{g} / \mathrm{L}$ for
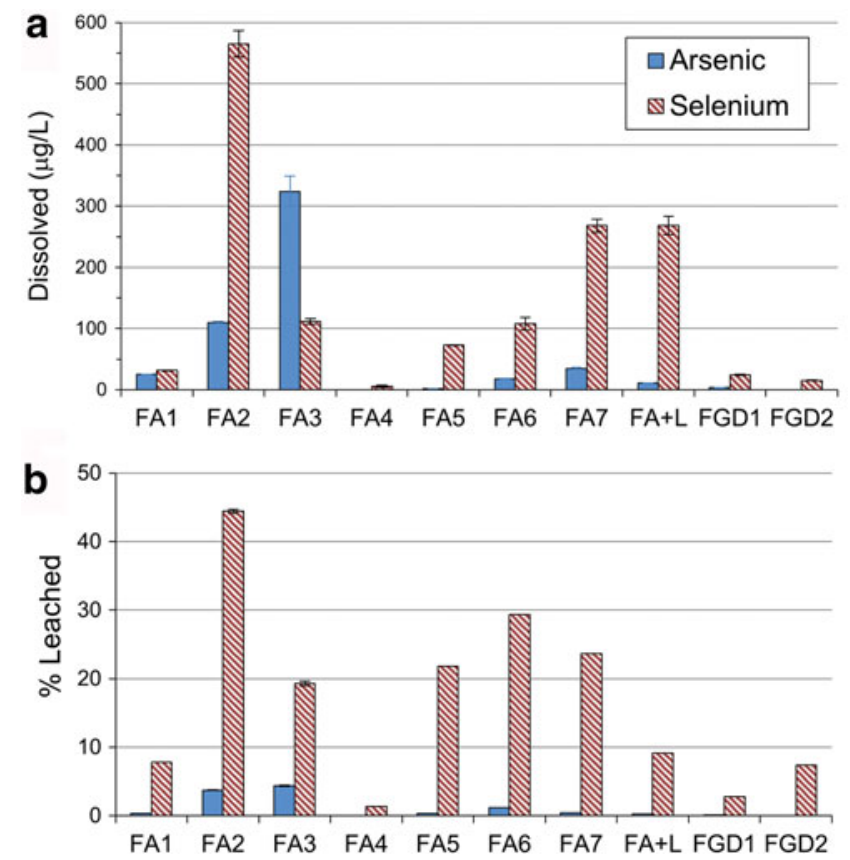

FIG. 1. Natural pH leaching results for ash materials mixed in Milli-Q water for $24 \mathrm{~h}$ : (a) dissolved arsenic and selenium. Each bar represents the average \pm 1 standard deviation of triplicate leachates; (b) percent of the total As or Se leached from the ash material. Error bars represent the propagated standard error of measurements of leached As or Se and the total ash material As or Se. Bars with no error bars represent instances of a single measurement of total As or Se in the ash material.

Se) and up to $324 \mathrm{mg} / \mathrm{L}$ for As and $565 \mu \mathrm{g} / \mathrm{L}$ for Se (Fig. 1a). The percent of total As leached was very low-under $5 \%$ for all samples (Fig. 1b). The percent of total Se leached was much greater, with the majority of the materials leaching between $4 \%$ and $45 \%$ of total Se (Fig. 1b). There were no correlations between dissolved As and total As concentration in the ash materials or between dissolved Se and total Se concentration in the ash materials (Supplementary Fig. S1a, b).

Dissolved As and dissolved Se concentrations did not increase with the $\mathrm{pH}$ of the leachate. Arsenic was poorly correlated with $\mathrm{pH}$, while Se showed no correlation $\left(R^{2}=0.29\right.$ and 0.0031 for $\mathrm{As}$ and $\mathrm{Se}$, respectively) (Supplementary Fig. S2). The $\mathrm{CaO} / \mathrm{SO}_{3}$ ratio in the ash material did correlate strongly with the natural pH of the fly ash samples (Supplementary Fig. S3a). However, there were no strong correlations between $\mathrm{CaO} / \mathrm{SO}_{3}$ ratio and dissolved As and Se concentrations in the natural $\mathrm{pH}$ leachate (Supplementary Fig. S3b, c).

Previous studies have shown that oxyanion leaching from ash materials is highly $\mathrm{pH}$-dependent, with $\mathrm{pH}$ typically predicted by the $\mathrm{Ca} / \mathrm{S}$ ratio (reported as $\mathrm{CaO} / \mathrm{SO}_{3}$ ) in the ash. $\mathrm{CaO}$-rich ash materials generally produce alkaline waters $(\mathrm{pH}$ 11-13), which can enhance desorption of oxyanions such as As and Se from ash particles but also decrease dissolved As and Se concentrations through incorporation into secondary calcium precipitates (e.g., ettringite) (Wang et al., 2009; Izquierdo and Querol, 2012). Ash materials with balanced $\mathrm{CaO} /$ $\mathrm{SO}_{3}$ ratios produced mildly alkaline waters ( $\mathrm{pH}$ 8-9) and may release some of the highest concentrations of As and Se due to $\mathrm{pH}$-induced desorption from metal-oxide mineral phases 
(Izquierdo and Querol, 2012). Ash materials with low $\mathrm{CaO} /$ $\mathrm{SO}_{3}$ ratios would produce acidic waters and generally display lower As and Se leaching due to the strong sorption of As and Se oxyanions to metal-oxide mineral phases in the ash (Catalano et al., 2012; Izquierdo and Querol, 2012).

Though the sorption affinity of As and Se to the fly ash particles generally decreases with solution $\mathrm{pH}$ when comparing sorption trends for a single sorbent, the same expectation may not necessarily hold when comparing across different sorbent types. The surface composition of the fly ash particles would also influence sorption/desorption processes. Moreover, secondary precipitates (such as Ca-arsenates) could be forming at high $\mathrm{pH}$ values, and the potential for these processes would also depend on fly ash composition.

\section{TCLP leaching}

All of the coal ash materials remained well under the maximum regulatory threshold limit for toxicity characteristic as defined by the TCLP test $(5,000 \mu \mathrm{g} / \mathrm{L}$ for As and $1,000 \mu \mathrm{g} / \mathrm{L}$ for Se) (Fig. 2a). In general, more than $10 \%$ of the total Se in the ash materials leached during the TCLP test while As leaching was mostly below $10 \%$ (Fig. 2b). There was little correlation $\left(R^{2}=0.27, p=0.13\right)$ between the total amount of As in the ash materials and the amount leached by TCLP (Fig. 2c). The total amount of Se in the ash material was a much better predictor $\left(R^{2}=0.81, p=0.0004\right)$ of the amount of Se leached by TCLP (Fig. 2d).

\section{Sediment/ash microcosms}

Concentration of dissolved As in the microcosms varied considerably by ash material (Fig. 3a), with concentrations ranging from 2 to $72 \mu \mathrm{g} / \mathrm{L}$ at $24 \mathrm{~h}$ and 1 to $61 \mu \mathrm{g} / \mathrm{L}$ at 14 days in the anaerobic microcosms and 0.5 to $111 \mu \mathrm{g} / \mathrm{L}$ at $24 \mathrm{~h}$ and 0.7 to $41 \mu \mathrm{g} / \mathrm{L}$ at 14 days in the aerobic microcosms (Fig. 3a). The percentage of total As leached in the microcosms (Fig. 3b) was generally less than the \%leached in both the Natural $\mathrm{pH}$ and TCLP tests. This result is likely due to readsorption of dissolved As onto sediment particles in the microcosm. Dissolved As generally increased over time in the anaerobic microcosm, while the trend was mixed in the aerobic microcosms. For some materials, dissolved As concentrations were greater in the anaerobic microcosms than the aerobic microcosms [consistent with our previous work (Schwartz et al., 2016b)], but for other ash materials the opposite was observed (Supplementary Fig. S4). Thus, the
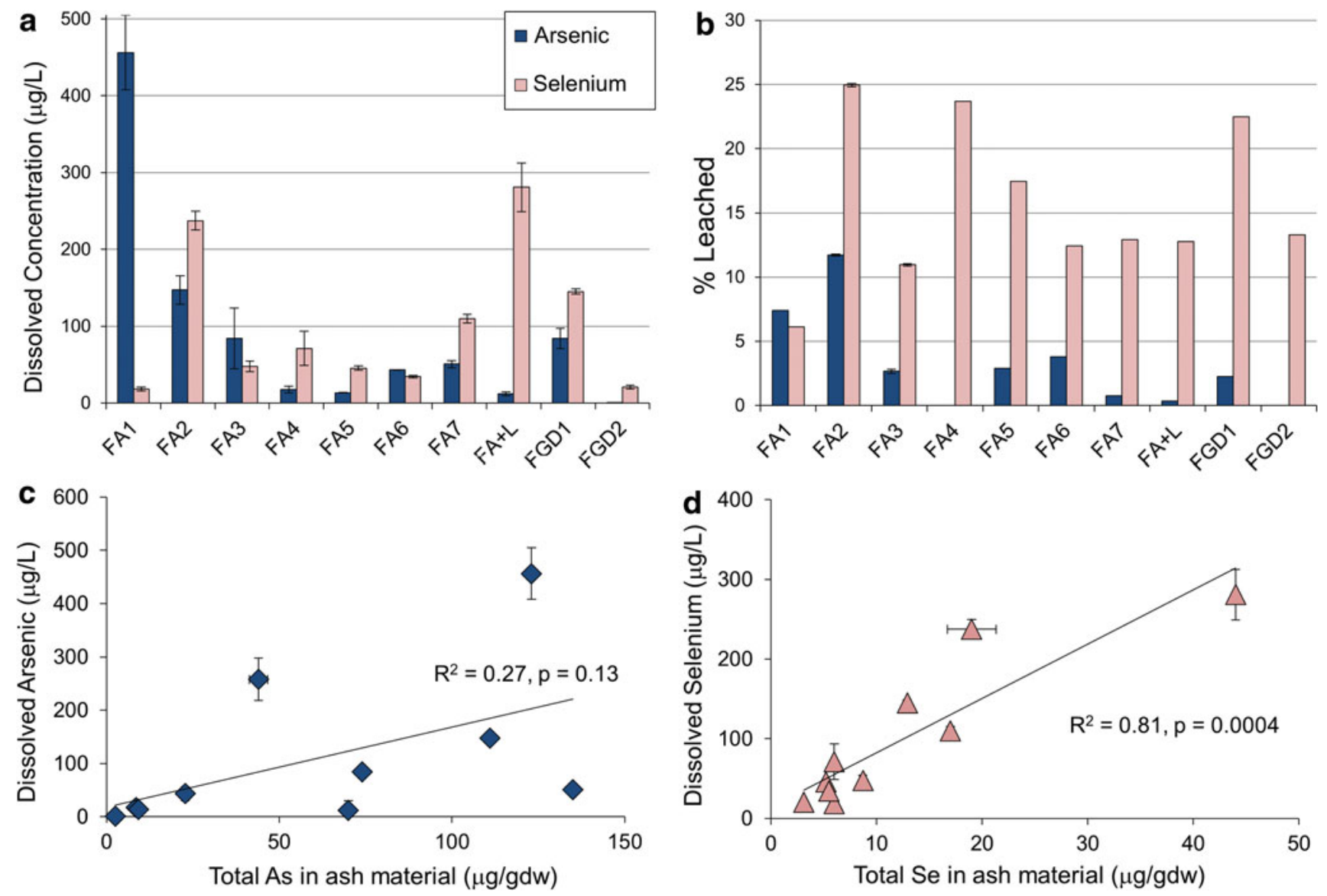

FIG. 2. TCLP leaching results for ash materials: (a) dissolved arsenic and selenium in TCLP leachate; (b) percent of total arsenic or selenium leached from ash material; (c) correlation between the total arsenic in ash material and the dissolved As in the TCLP leachate; and (d) correlation between the total Se in ash material and dissolved Se in TCLP leachate. Each bar and data point represents the average \pm 1 standard deviation of triplicate leachates. Bars or data points with no error bars represent instances of a single measurement of total As or Se in the ash material. TCLP, Toxicity Characteristic Leaching Protocol. 

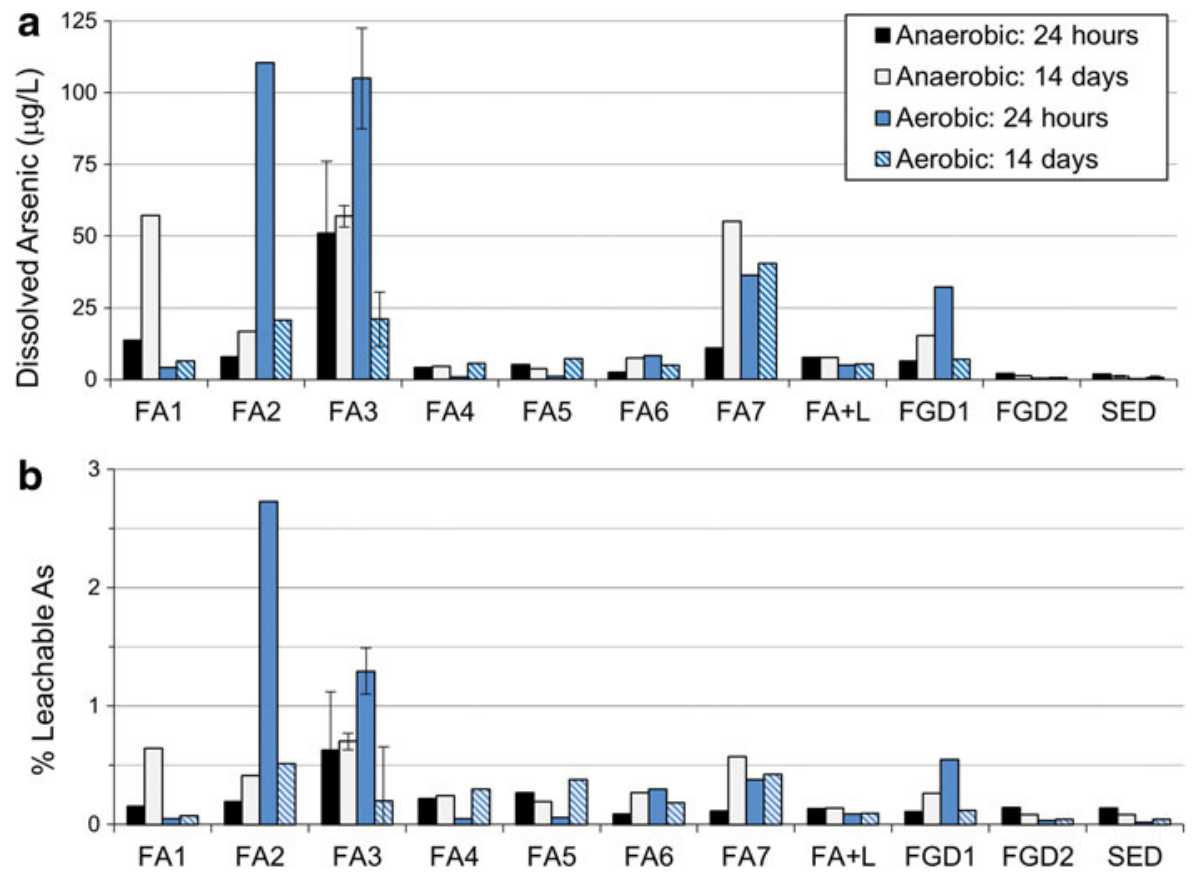

FIG. 3. (a) Total dissolved arsenic $(0.2 \mu \mathrm{m}$ filtered fraction) in sediment-ash microcosms. Bars represent single microcosms with exception of FA3 and SED (sediment only microcosm, no ash) where bars represent the average \pm 1 standard deviation of triplicate microcosms; (b) percent of total As (sediment As+Ash As) leached. Bars with no error bars represent instances of a single measurement of total As or Se in ash material. leaching of dissolved As in the microcosms could not be predicted solely by aerobic and anaerobic conditions.

Dissolved Se concentrations also varied between different ash materials. Values ranged from 4 to $123 \mu \mathrm{g} / \mathrm{L}$ at 1 day and 0.7 to $17 \mu \mathrm{g} / \mathrm{L}$ at 14 day in the anaerobic microcosms and 6 to $249 \mu \mathrm{g} / \mathrm{L}$ at 1 day and 5 to $99 \mu \mathrm{g} \mathrm{L}^{-1}$ at $14 \mathrm{~d}$ in the aerobic microcosms (Fig. 4a). The Se \%leached in the microcosms was also generally lower than the \%leached in the Natural $\mathrm{pH}$ and TCLP tests. This is again likely due to Se re-adsorption onto microcosm sediment particles. Selenium concentrations generally declined over time in both the anaerobic and aerobic microcosms. However, at both the 24-h and 14-day time points, dissolved Se concentration was generally greater in the aerobic microcosms relative to the anaerobic microcosms (Supplementary Fig. S5). In the anaerobic microcosms, the ash materials produced a pulse of Se at $24 \mathrm{~h}$, which decreased to less than $20 \mu \mathrm{g} / \mathrm{L}$ at 14 days, suggesting that regardless of ash chemistry, anaerobic conditions were effective in limiting selenium solubility.

In the anaerobic microcosms, total dissolved As was generally correlated with the total arsenic content in the coal ash at both the 24-h and 14-day time points $\left(R^{2}=0.62, p=0.007\right.$ and $R^{2}=0.87, p<0.001$, respectively; Fig. 5a). This relationship was even stronger at the 14 days time point when only fly ash samples with no lime treatment were considered $\left(R^{2}=0.98, p<0.001\right)$. In anaerobic microcosms, there was a
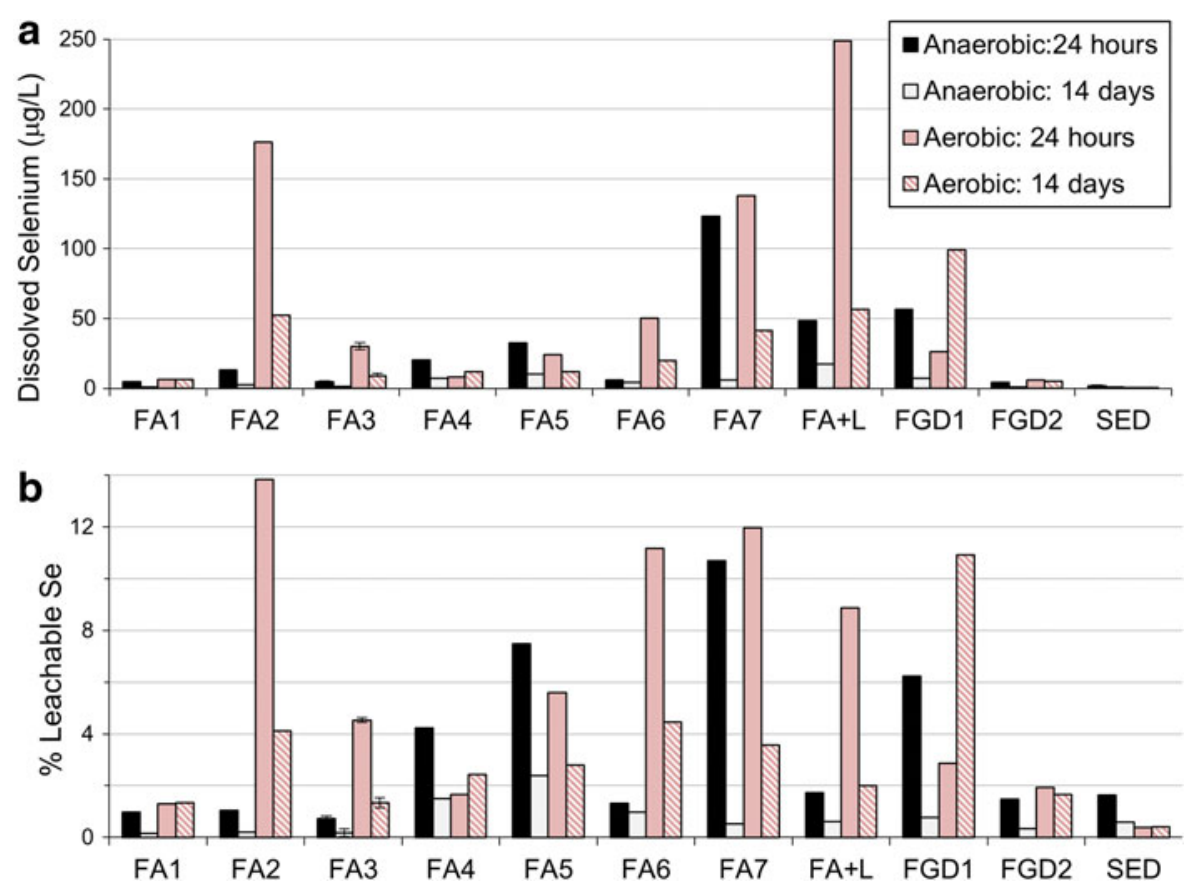

FIG. 4. (a) Total dissolved selenium $(0.2 \mu \mathrm{m}$ filtered fraction) in sediment-ash microcosms.. Bars represent single microcosms with the exception of FA3 and SED (sediment only microcosm, no ash) where bars represent the average \pm 1 standard deviation of triplicate microcosms; (b) percent of the total Se (sediment Se+Ash Se) leached. Bars with no error bars represent instances of a single measurement of total As or Se in ash material. 

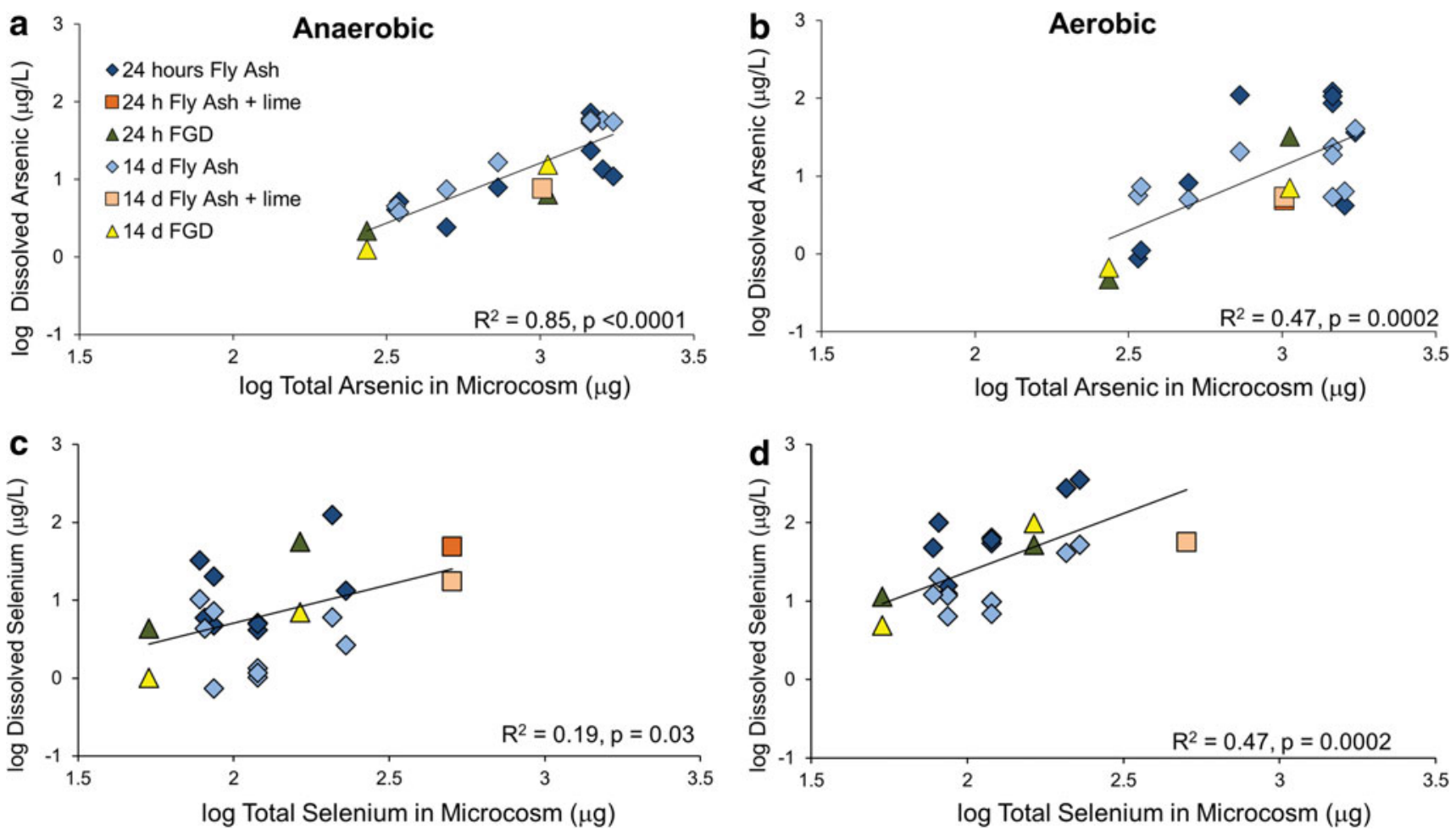

FIG. 5. Correlations between total element content in ash material and dissolved element content in sediment/ash slurry microcosms: (a) arsenic in anaerobic microcosms; (b) arsenic in aerobic microcosms; (c) selenium in anaerobic microcosms; and (d) selenium in aerobic microcosms. Each data point represents a single microcosm.

weak correlation between the percentage of the total As leached at 14 days in the microcosms and the total Fe content of the ash materials $\left(R^{2}=0.41, p=0.05\right)$ (Supplementary Table S3). Yet, there was no correlation between dissolved As and dissolved Fe concentrations at either time point (Supplementary Table S3) as might be expected if the mechanism of As leaching occurred through the reductive dissolution of Fe oxides. The lack of correlation between dissolved As and dissolved Fe concentrations may be due to Fe precipitation reactions in the microcosms or $\mathrm{Fe}$ adsorption to the solid phase following reductive dissolution. Dissolved $\mathrm{Se}$ in the aerobic microcosms could generally be correlated with the total Se content of the ash material at both the 24-h and 14-day time points $\left(R^{2}=0.73, p=0.002\right.$ and $R^{2}=0.64, p=0.005$, respectively; Fig. 5d). This relationship was not found in the anaerobic microcosms (Fig. 5c). No correlations were found between the dissolved Se content of the aerobic and anaerobic microcosms and Fe content.

The $\mathrm{pH}$ values in the microcosms varied with ash material, with the highest $\mathrm{pH}$ observed in the microcosm amended with lime-treated fly ash (FA+L) (Supplementary Fig. S6). In our microcosms, no significant correlations between $\mathrm{CaO} / \mathrm{SO}_{3}$ ratio and $\mathrm{As}$ and $\mathrm{Se}$ leaching magnitude were observed, likely due to $\mathrm{pH}$ buffering by the sediment/water in the slurries that maintained the $\mathrm{pH}$ at neutral to moderately alkaline conditions for most microcosms. The microcosm amended with limetreated ash was the one exception to this buffering, and a high dissolved Se concentration was observed at the $24 \mathrm{~h}$ time point when the $\mathrm{pH}$ was highly alkaline ( $\mathrm{pH} 12.29)$. Overall, $\mathrm{pH}$ did not appear to affect the percentage of arsenic and selenium leached from the ash materials (Supplementary Fig. S7).
Dissolved Ca concentrations in the microcosms varied by ash material, and with the exception of the microcosm amended with FA4, dissolved Ca concentrations were higher in aerobic microcosms compared to anaerobic microcosms (Supplementary Fig. S8). High Ca content in the ash material did not result in higher concentrations of dissolved calcium in either the aerobic or anaerobic microcosms (Supplementary Fig. S9). Furthermore, given similar concentrations of $\mathrm{Ca}$ in the ash material, FGD and lime-treated fly ash microcosms leached more calcium than fly ash-amended samples (FA4 and FA5). Calcium content of the ash material did not correlate with the percent leached for either As or Se (Supplementary Table S3).

\section{Interaction between ash chemistry and redox conditions in microcosms}

Measurements of dissolved sulfate and $\mathrm{Fe}$ in the microcosms indicated a clear difference in redox potential between the anaerobic and aerobic microcosms. Dissolved sulfate concentrations varied widely across ash material. Over 14 days, sulfate reduction appeared to occur in some microcosms but not in others (Supplementary Fig. S10). However, acid volatile sulfide concentrations in aerobic microcosms were one to two orders-of-magnitude lower relative to concentrations in the anaerobic microcosms, which ranged from 0.01 to $0.7 \mu \mathrm{mol} / \mathrm{g}$ of slurry (data not shown), confirming that there was a difference in redox potential between the aerobic and anaerobic microcosms.

Total dissolved Fe concentrations also varied by ash material and according to the redox condition in the microcosms. At 
the preamendment time point $(-1 \mathrm{~h})$, the anaerobic microcosms contained an average of $4.60 \mathrm{mg} / \mathrm{L}$ total dissolved Fe while the aerobic microcosms contained an average of $0.033 \mathrm{mg} / \mathrm{L}$ total dissolved $\mathrm{Fe}$, indicating that Fe-reduction and $\mathrm{Fe}(\mathrm{II})$ release was occurring in the anaerobic microcosms (data not shown). At both $24 \mathrm{~h}$ and 14 days after ash addition, the anaerobic microcosms generally contained higher levels of total dissolved Fe $(0.002-37 \mathrm{mg} / \mathrm{L})$ than the aerobic microcosms (0.001-0.007 mg/L) (Supplementary Fig. S11a). The total Fe content of the ash material did not appear to correspond to the magnitude of iron released in either the anaerobic (Supplementary Fig. S11b) or the aerobic (Supplementary Fig. S11c) microcosms.

In these sediment/ash microcosms, changes in redox potential did not impact the mobility of As and Se to the same degree. In contrast to As, dissolved Se decreased over time in both the aerobic and anaerobic microcosms, indicative of different geochemical reaction pathways for the two elements. With Se, much greater amounts were leached under aerobic conditions, as would be expected from previous research (Schwartz et al., 2016b). In anaerobic microcosms, an initial pulse of Se was released and then immobilized over the 14 days incubation. In general, anaerobic conditions appear effective in immobilizing Se, though an initial release of Se may still be a concern, depending on the flow dynamics of the system. Ash chemistry parameters, such as Fe and Ca contents, did not correlate with the amount of Se leached in the microcosms. Total Se in the ash material did correlate with dissolved Se in the aerobic microcosms, yet the strength of the correlation $\left(R^{2}=0.64\right.$ at 14 days $)$, indicates that other factors in addition to redox and total element content were influencing Se leaching potential in the microcosms.

Arsenic leaching could not be predicted based on redox potential. The lack of a consistent pattern in As leaching based on redox potential is different than the results of our previous work involving fly ash from Tennessee Plant \#1 (FA2) (Schwartz et al., 2016b). This previous study showed greater amounts of As leaching under anaerobic conditions and greater amounts of Se leaching under aerobic conditions. While the experimental designs in both studies were nearly identical, this study utilized sediment with an observable red color $(37.1 \mathrm{mg} / \mathrm{gdw} \mathrm{Fe})$, whereas the microcosms in our previous study contained sediment with much lower $\mathrm{Fe}$ content (3.64 mg/gdw) and an observable brown color (suggesting greater organic carbon content).

The differences in sediment chemistry may have affected sorption of dissolved arsenic and selenium in the microcosms. Certain forms of $\mathrm{As}$ and $\mathrm{Se}$ such as arsenate and selenite species have a high affinity for Fe-oxide minerals (Balistrieri and Chao, 1990; Smedley and Kinniburgh, 2002), which could explain some differences with our previous experiment. Natural organic matter (NOM) can also impact As and Se solubility through competition for sorption sites, formation of oxyanion-NOM colloids that would fall in the "dissolved" fraction, direct oxidation/reduction reactions with As and Se, and indirect effects such as organic substrate type and availability that could influence redox potential (Redman et al., 2002; Gadd, 2004; Wang and Mulligan, 2006; Sharma et al., 2015). Differences in the sediment microbial community structure impact contaminant mobility as microbes can mobilize contaminants either through direct oxidation and reduction reactions or indirectly through the reduction of iron oxides and minerals (Gadd, 2004). Together these results highlight the complexities associated with using sediment microcosms for leaching assessments.

In our limited dataset, the As leaching results from our microcosms showed that ash chemistry, particularly the total arsenic content of the material might be used to predict As leaching potential from coal ash in anaerobic scenarios. Previous leaching studies utilizing the LEAF tests and mimicking ash impoundment leaching scenarios have not observed a relationship between total element concentration in coal ash and the magnitude of element leaching-perhaps because they were conducted under aerobic conditions (Thorneloe et al., 2010; Catalano et al., 2012). During coal combustion, As is volatilized into the flue gas stream and then condenses on the surface of aluminosilicate particles as the flue gas cools (Hulett et al., 1980). These aluminosilicate phases can have Fe microdomains. Since As has a high affinity for iron oxide minerals (Smedley and Kinniburgh, 2002), association with Fe-rich aluminosilicates is possible (Veselská et al., 2013). When the ash material is exposed to anaerobic conditions, it could result in the reductive dissolution of Fe phases and the release of As into solution. This would explain the much higher concentrations of dissolved As in our anaerobic microcosms compared with the aerobic microcosms and would explain the correlation between total As content in the ash and dissolved As in the leachates under anaerobic conditions. The much greater concentrations of dissolved $\mathrm{Fe}$ in the anaerobic microcosms also provide further evidence for As release by reductive dissolution of $\mathrm{Fe}$ phases. The correlation between total As content in fly ash and dissolved As under anaerobic conditions $\left(R^{2}=0.98\right.$ at 14 days) in our dataset indicates that total As content of the fly ash might be used as a first approximation of As leaching risk from fly ash in an ash spill situation where the ash may mix with anaerobic sediments.

In sum, As leaching chemistry from coal ash appears to be very complex and highly influenced by environmental parameters, such as sediment organic content, $\mathrm{pH}$, redox state, and soil microbial community, which drives soil redox conditions. It would be difficult to construct leaching models to predict As mobilization for a generalized ash spill and/or disposal situations. More information is needed regarding ambient conditions at the site such as the mixing of ash materials with sediments as well as the sediment types and their levels of organic carbon. Arsenic also undergoes multiple sorption and desorption reactions and precipitation reactions. These reactions can occur at different timescales and cause increases and decreases of dissolved concentrations, which brings into question whether coal ash leaching potential can reasonably be assessed by single time point leaching protocols under environmentally relevant conditions. The maximum dissolved As concentrations were typically observed after $24 \mathrm{~h}$ in most of the aerobic microcosms, but maximum dissolved concentrations were observed at 14 days for most of the anaerobic microcosms. If leaching potential is assessed at only $24 \mathrm{~h}$, the risk of As leaching may be underestimated in some scenarios.

\section{Ranking leaching potential}

To assess leaching potential, we compared the results of the four leaching tests in two ways: (1) comparing the amount of leached As or Se per g of ash tested, and (2) comparing the 
percent leached of the total As and total Se. The amount of leachable As or Se per $g$ of ash for any given ash material varied widely across tests, indicating the important role of geochemical conditions in leaching (Supplementary Fig. S12). The percent of contaminant leached for each ash also varied across tests, and the percent of Se leached was noticeably higher than As, as noted in the previous section. This result suggests that $\mathrm{Se}$ on the ash is more reactive and susceptible to leaching regardless of the geochemical conditions.

Comparative leaching potentials were evaluated by ranking the 10 ash samples based on their leachable As and Se contents (per g ash) in each assay. In this respect, the materials were assigned an integer from 1 to 10 , with 10 corresponding to the highest amount leached per $g$ ash (defined as the highest leaching potential) and 1 corresponding to the lowest amount leached per $g$ ash (i.e., the smallest leaching potential) for each test (Fig. 6). The four leaching tests gave reasonably good agreement in categorizing the ash materials. For As, three out of four tests agreed in ranking FA2, FA3, and FA7 as having the highest leaching potential, and FA4, FA5, and FGD2 as having the lowest leaching potential (Supplementary Fig. S13). For Se, three out of four tests agreed in ranking FA2, FA7, and FA + L as having the highest leaching potential, and FA1 and FGD2 as having the lowest leaching potential (Supplementary Fig. S13). Only one ash material, FGD1, was categorized by the tests as having both a high and low leaching potential. Two ash materials (FA2 and FA7) were predicted to be high leaching potential for both As and Se.

Ash materials were also ranked according to the \% of total As and \% of total Se that leached in each assay. The ranking of the ashes with high percentages and ashes with low percentages were not as consistent between the tests. For example, all four tests categorized FA2 as high \% leachable As and three out of four tests ranked FA4 and FGD2 as low \%leachable As (Supplementary Fig. S14). However, three ash materials (FA4, FA6, and FGD1) appeared in both highand low-risk categories. For Se, three out of four tests categorized FA2 as high \% leachable Se, and there was little agreement (only two out of four tests) on the lowest leaching potential ashes (Supplementary Fig. S15). Four ash materials appeared in both the low and high categories for \%leachable Se (FA2, FA4, FA6, and FGD1). The inconsistency of rankings based on \% leachable Se and As highlight the importance of environmental conditions for understanding the degree of soluble Se and As in coal ash.

\section{Future directions for predicting disposal risks}

Results of the ash rankings based on leachable As and leachable Se (per g ash) were generally consistent between the tests despite the relative simplicity of the protocols. This result suggests that a 24-h single point leaching test of leachable As and leachable Se content could give a good first estimate of leaching potential and may present a way to identify ash samples for more in depth risk assessment. Yet, to develop a true understanding of the magnitude of potential leaching, it is crucial to select a leaching test that adequately mimics the ash disposal or spill scenario.

Our results demonstrate that geochemical conditions greatly impact the overall amount of contaminant leached for both As and Se, and the selection of just one test to assess leaching potential could result in an underestimate of leaching if that test is not representative of disposal conditions. Current
FIG. 6. Comparison of $10 \mathrm{coal}$ ash samples tested in leaching studies (TCLP, DI water leaching, and sediment/ash microcosm tests). Ash samples were assigned integer values between 1 and 10 based on (a) leachable arsenic per $\mathrm{g}$ of ash; and (b) leachable selenium per $g$ of ash at the $24 \mathrm{~h}$ time point for each leaching test.
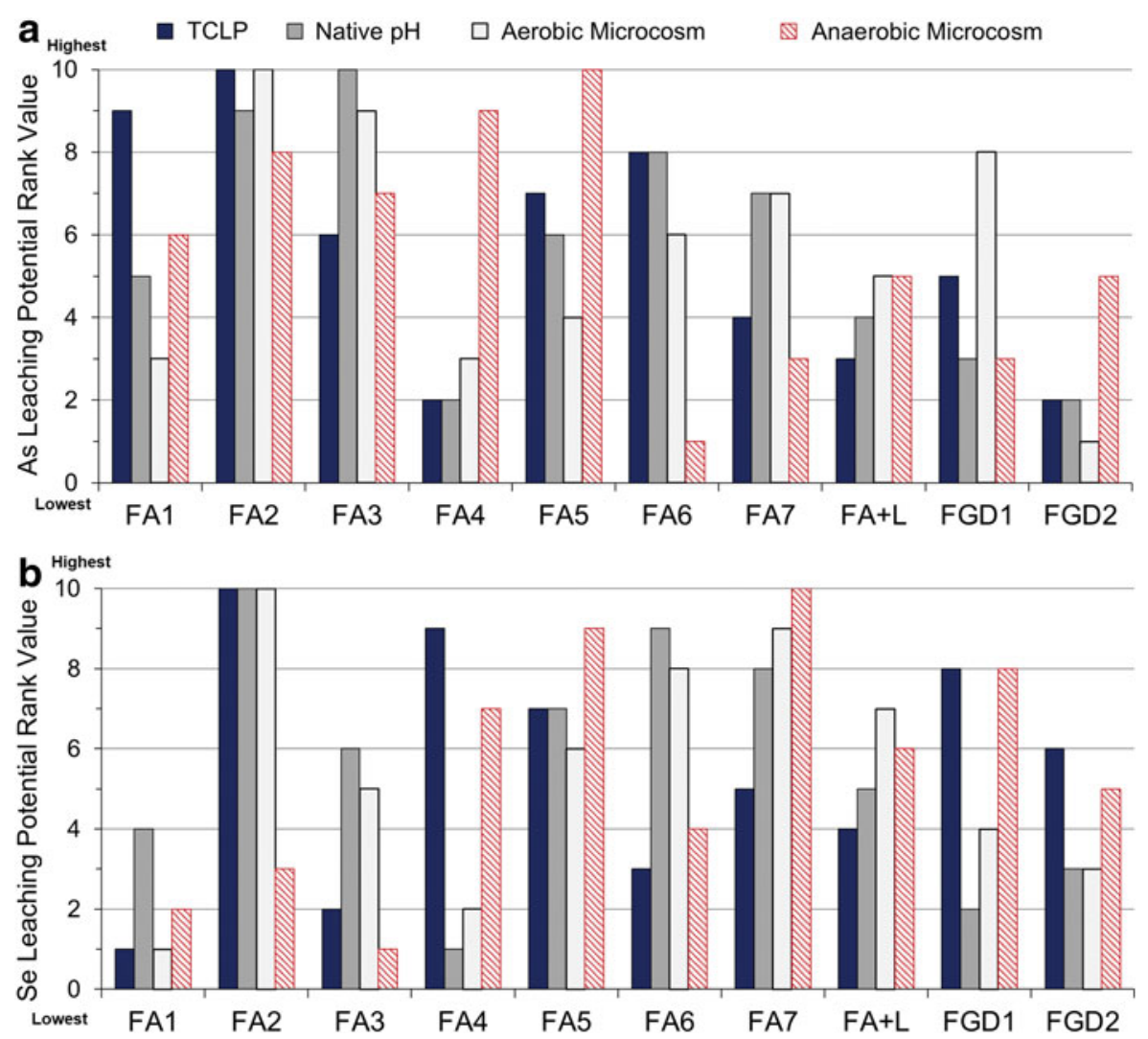
disposal options for coal ash consist of wet storage in impoundments and dry landfilling in either monofills or, lessfrequently, in mixed compartments with municipal waste. Each of these disposal scenarios presents a unique geochemical environment that varies from site to site. Given these complexities, perhaps the best approach for assessing coal ash disposal risk is to move toward a situational framework. Just as the National Pollution Discharge Elimination System (NPDES) permits in the United States are written specifically for individual outfalls from power plants, a coal ash disposal plan could also be tailored for the specific conditions of the coal ash disposal sites. In this way, disposal requirements could be written for specific elements of interest given the typical coal source, combustion parameters, air pollution capture devices of the particular plant, and disposal track for solid wastes. Site-specific, situational risk assessments present the best option for ash materials, especially for contaminants such as As and Se that are known to undergo multiple biogeochemical transformations that influence mobility and exposure.

\section{Acknowledgments}

We thank Kaitlyn Porter for her assistance with ICP-MS measurements. This work was supported by the National Science Foundation (CBET-1235661 and CBET-1510965). G.E.S. was partly supported by a doctoral scholarship from the Environmental Research and Education Foundation. The effort of A.L.P. was supported by Duke's Program in Environmental Health (ITEHP) Training Grant from the National Institute of Environmental Health Sciences (T32-ES021432).

\section{Supporting Information}

The supporting information contains additional descriptions of sample preparation and analysis, statistical data, additional figures on microcosm geochemistry, and correlations between the individual leaching tests.

\section{Author Disclosure Statement}

No competing financial interests exist.

\section{References}

Balistrieri, L.S., and Chao, T.T. (1990). Adsorption of selenium by amorphous iron oxyhydroxide and manganese dioxide. Geochim. Cosmochim. Acta. 54, 739.

Catalano, J.G., Huhmann, B.L., Luo, Y., Mitnick, E.H., Slavney, A., and Giammar, D.E. (2012). Metal release and speciation changes during wet aging of coal fly ashes. Environ. Sci. Technol. 46, 11804.

Chou, C.-L. (2012). Sulfur in coals: A review of geochemistry and origins. Int. J. Coal Geol. 100, 1.

Córdoba, P., Ochoa-Gonzalez, R., Font, O., Izquierdo, M., Querol, X., Leiva, C., López-Antón, M.A., Díaz-Somoano, M., Rosa Martinez-Tarazona, M., Fernandez, C., et al. (2012). Partitioning of trace inorganic elements in a coalfired power plant equipped with a wet Flue Gas Desulphurisation system. Fuel 92, 145.

Deonarine, A., Bartov, G., Johnson, T.M., Ruhl, L., Vengosh, A., and Hsu-Kim, H. (2013). Environmental impacts of the Tennessee Valley Authority Kingston coal ash spill. 2. Effect of coal ash on methylmercury in historically contaminated river sediments. Environ. Sci. Technol. 47, 2100.
Finkelman, R.B. (1995). Modes of occurrence of environmentallysensitive trace elements in coal. In D.J. Swaine and F. Goodarzi, Eds., Environmental Aspects of Trace Elements in Coal. Springer: Springer Netherlands, pp. 24-50.

Gadd, G.M. (2004). Microbial influence on metal mobility and application for bioremediation. Geoderma 122, 109.

Hower, J.C., Trimble, A.S., Eble, C.F., Palmer, C.A., and Kolker, A. (1999). Characterization of fly ash from low-sulfur and high-sulfur coal sources: Partitioning of carbon and trace elements with particle size. Energ Sources 21, 511.

Hulett, L.D., Weinberger, A.J., Northcutt, K.J., and Ferguson, M. (1980). Chemical species in fly ash from coal-burning power plants. Science 210, 1356.

Hutchinson, T.J., Basappa, L., Dikshit, A., Luo, Y., Catalano, J.G., and Giammar, D.E. (2012). Fate of metals in fly ash during aging in laboratory-scale ash impoundments. Environ. Eng. Sci. 29, 1085.

Izquierdo, M., and Querol, X. (2012). Leaching behaviour of elements from coal combustion fly ash: An overview. Int. J. Coal Geol. 94, 54.

Kolker, A. (2012). Minor element distribution in iron disulfides in coal: A geochemical review. Int. J. Coal Geol. 94, 32.

Kosson, D.S., Sanchez, F., Kariher, P., Turner, L.H., Delapp, R., and Seignette, P. (2009). Characterization of Coal Combustion Residues from Electric Utilities-Leaching and Characterization Data. EPA Office of Research and Development, Ed. National Risk Management and Research Laboratory, Research Triangle Park, NC.

Kosson, D.S., van der Sloot, H.A., Garrabrants, A.C., and Seignette, P. (2014). Leaching Test Relationships, Laboratoryto-Field Comparisons and Recommendations for Leaching Evaluation Using the Leaching Environmental Assessment Framework (LEAF). Cincinnati, OH: Report US Environmental Protection Agency.

Liu, Y.-T., Chen, T.-Y., Mackebee, W.G., Ruhl, L., Vengosh, A., and Hsu-Kim, H. (2013). Selenium speciation in coal ash spilled at the Tennessee Valley Authority Kingston site. Environ. Sci. Technol. 47, 14001.

Luoma, S.N., and Presser, T.S. (2009). Emerging opportunities in management of selenium contamination1. Environ. Sci. Technol. 43, 8483.

Meij, R. (1994). Trace element behavior in coal-fired power plants. Fuel Process. Technol. 39, 199.

Redman, A.D., Macalady, D.L., and Ahmann, D. (2002). Natural organic matter affects arsenic speciation and sorption onto hematite. Environ. Sci. Technol. 36, 2889.

Ruhl, L., Vengosh, A., Dwyer, G., Hsu-Kim, H., Schwartz, G., Romanski, A., and Smith, S.D. (2012). The impact of coal combustion residue effluent on water resources: A North Carolina example. Environ. Sci. Technol. 46, 12226.

Schwartz, G.E., Redfern, L.K., Ikuma, K., Gunsch, C.K., Ruhl, L.S., Vengosh, A., and Hsu-Kim, H. (2016a). Impacts of coal ash on methylmercury production and the methylating microbial community in anaerobic sediment slurries. Environ. Sci. Process. Impacts 18, 1427.

Schwartz, G.E., Rivera, N., Lee, S.-W., Harrington, J.M., Hower, J.C., Levine, K.E., Vengosh, A., and Hsu-Kim, H. (2016b). Leaching potential and redox transformations of arsenic and selenium in sediment microcosms with fly ash. Appl. Geochem. 67, 177.

Sharma, V.K., McDonald, T.J., Sohn, M., Anquandah GAK, Pettine, M., and Zboril, R. (2015). Biogeochemistry of selenium. A review. Environ. Chem. Lett. 13, 49. 
Sharma, V.K., and Sohn, M. (2009). Aquatic arsenic: Toxicity, speciation, transformations, and remediation. Environ. Int. 35, 743.

Smedley, P.L., and Kinniburgh, D.G. (2002). A review of the source, behaviour and distribution of arsenic in natural waters. Appl. Geochem. 17, 517.

Thorneloe, S.A., Kosson, D.S., Sanchez, F., Garrabrants, A.C., and Helms, G. (2010). Evaluating the fate of metals in air pollution control residues from coal fired power plants. Environ. Sci. Technol. 44, 7351.

Tratnyek, P.G., Reilkoff, T.E., Lemon, A.W., Scherer, M.M., Balko, B.A., Feik, L.M., and Henegar, B.D. (2001). Visualizing redox chemistry: Probing environmental oxidation-reduction reactions with indicator dyes. Chem. Educ. 6, 172.

United States Energy Information Administration. (2014). Spot Coal Price Trends Vary Across Key Basins During 2013. Available at: www.eia.gov/todayinenergy/detail.php?id=14631 (accessed August 31, 2017).

United States Environmental Protection Agency. (1992). Method 1311: Toxicity Characteristic Leaching Procedure. Washington, DC: United States Environmental Protection Agency.

United States Environmental Protection Agency. (2007). Coal Combustion Waste Damage Assessments. Available at: http:// graphics8.nytimes.com/packages/pdf/national/07sludge_EPA.pdf (accessed August 31, 2017).

United States Environmental Protection Agency. (2012a). Method 1313: Liquid Solid Partitioning as a Function of Extract pH using a Parallel Batch Extraction Procedure. Washington, DC: United States Environmental Protection Agency.

United States Environmental Protection Agency. (2012b). Method 1316: Liquid-Solid Partitioninig as a Function of
Liquid-to-Solid Ratio in Solid Materials Using a Parallel Batch Procedure. Washington, DC: United States Environmental Protection Agency.

United States Environmental Protection Agency. (2013a). Method 1314: Liquid-Solid Partitioning as a Function of Liquid-Solid Ratio for Constituents in Solid Materials Using an Up-Flow Percolation Column Procedure. Washington, DC: United States Environmental Protection Agency.

United States Environmental Protection Agency. (2013b). Method 1315: Mass Transfer Rates of Constituents in Monolithic or Compacted Granular Materials Using a Semi-Dynamic Tank Leaching Procedure. Washington, DC: United States Environmental Protection Agency.

United States Environmental Protection Agency. (2013c). Technical Development Document for the Proposed Effluent Limitations Guidelines and Standards for the Steam Electric Power Generating Point Source Category. Washington, DC: United States Environmental Protection Agency.

Vejahati, F., Xu, Z., and Gupta, R. (2010). Trace elements in coal: Associations with coal and minerals and their behavior during coal utilization-A review. Fuel 89, 904.

Veselská, V., Majzlan, J., Hiller, E., Peťková, K., Jurkovič, L', Durža, O., and Voleková-Lalinská, B. (2013). Geochemical characterization of arsenic-rich coal-combustion ashes buried under agricultural soils and the release of arsenic. Appl. Geochem. 33, 153.

Wang, S., and Mulligan, C.N. (2006). Effect of natural organic matter on arsenic release from soilsand sediments into groundwater. Environ. Geochem. Health 28, 197.

Wang, T., Wang, J., Tang, Y., Shi, H., and Ladwig, K. (2009). Leaching characteristics of arsenic and selenium from coal fly ash: Role of calcium. Energ Fuels 23, 2959. 